\title{
UBIQUITIN CYTOCHEMICAL CHANGES DURING AZASERINE-INITIATED PANCREATIC CARCINOGENESIS*
}

\author{
S. Tóth, C. VAstagh, Z. PÁlfia and G. RéZ** \\ Department of General Zoology, Eötvös Loránd University, P.O. Box 330, H-1445 Budapest, Hungary
}

(Received: January 10, 2001; accepted: March 2, 2001)

\begin{abstract}
The ubiquitin (Ub)- proteasome proteolytic system is highly selective, and the specific proteins involved in cell division, growth, activation, signaling and transcription are degraded at different rate depending on the physio-pathological state of the cell. Ubiquitination serves first of all as a signal for protein degradation of short-lived and abnormal proteins under several stressful conditions. The immunocytochemical localization of $\mathrm{Ub}$ in some malignant tumours has recently been presented and differences in Ub expression has been observed during malignant transformation. Change in the level of $\mathrm{Ub}$ and $\mathrm{Ub}$-conjugated proteins might reflect a higher metabolic-catabolic ratio in neoplastic cells. Most studies have been focused on the malignant stage of tumour progression, and only a few papers have dealt with the change in $\mathrm{Ub}$ and $\mathrm{Ub}$-protein conjugates level during the whole progression. To address this problem, we applied an azaserine-induced pancreatic carcinogenesis model, in which premalignant and malignant stages were investigated throughout the progression. The level of $\mathrm{Ub}$ immunoreactivity was measured in nucleus and cytoplasm by electron microscopic immunocytochemical and morphometrical methods. We found a significant increase of $\mathrm{Ub}$ level in the nucleus and the cytoplasmic area in premalignant atypical acinar cell nodule (AACN) cells and in malignant adenocarcinoma in situ (CIS) cells at month 20 after initiation.
\end{abstract}

Keywords: Ubiquitin - immunocytochemistry - morphometry - carcinogenesis - tumour progression

\section{INTRODUCTION}

Several distinct mechanisms are responsible for intracellular protein degradation. Among these, the ubiquitin (Ub)-mediated proteasome-dependent proteolytic system is highly selective, and the specific proteins governing cell division, growth, activation, signaling and transcription are degraded at greatly different rates $[4,7,13]$. Ubiquitination serves as a signal for protein degradation of short-lived and abnormal proteins under stressful conditions such as toxic and viral injuries, high temperature, nutritional deprivation [9].

The role of $\mathrm{Ub}$ in pathological processes other than neurodegenerative diseases [2, $3,7]$ has been investigated systematically only in the last few years. Immuno-

\footnotetext{
* Dedicated to Professor János Kovács on the occasion of his 70th birthday.

**Corresponding author; e-mail: grez@cerberus.elte.hu
} 
cytochemical localization of $\mathrm{Ub}$ has recently been reported in several malignant tumours [14] and alteration in Ub expression has been observed during malignant transformation $[8,14]$. The change of $\mathrm{Ub}$ and $\mathrm{Ub}$-conjugated protein level might reflect a higher metabolic-catabolic ratio in neoplastic sells [14].

The Ub-proteasome proteolytic apparatus plays an important role in cell cycle progression, since it selectively degrades nuclear oncoproteins such as cyclins, c-fos, cmyc, p53 $[5,7,16]$. Moreover, several cell surface receptors were shown to be ubiquitinated, suggesting that Ub-proteasome proteolytic system could be involved in their turnover $[6,31]$. This observation confirmed the importance of this specific proteolytic system in some steps of signal transduction of growth factors. These results suggest a direct/indirect effect of different protein ubiquitinylation on malignant transformation and tumour progression.

Recently, a down-regulation of $\mathrm{Ub}$ gene expression was revealed during differentiation of human leukemia cells [28], but an increased expression in neuroblastoma cells [18], and a heavy increase of Ub level was found throughout hepatocellular carcinoma progression [25]. These results confirmed that Ub level highly depends on the differentiational state and type of the tumour cell. Most studies are focused on the malignant stage of tumour progression $[8,15,17,24,29,30]$, but only a few papers have dealt with the change in level of $\mathrm{Ub}$ and $\mathrm{Ub}$-protein conjugates during the whole progression $[25,26]$.

To address this problem, we applied a pancreatic carcinogenesis model [20, 21], in which azaserine was used as initiator and a pancreatotrophic diet as promoter. During the progression of adenocarcinoma, several tumours exist in the same pancreas $[20,21]$. Firstly, premalignant atypical acinar cell nodules (AACN) appear, some of which develop benign adenomas and then malignant adenocarcinoma in situ (CIS) [20,21]. Cell types investigated in this study were in the aforementioned different stages of tumour progression.

Ub level was morphometrically measured in nucleus and cytoplasm by an electron microscopic immunocytochemical method. We found a significant increase of Ub level in nuclear and cytoplasmic area in premalignant (especially in month $5 \mathrm{AACN}$ ) cells and in malignant CIS cells at month 20 after initiation.

\section{MATERIALS AND METHODS}

\section{Animals and treatments}

Five-week-old male Wistar rats (purchased from Humán Co., Gödöllő, Hungary) were fed ad libitum with a standard commercial laboratory diet (Charles River Hungary Ltd., Budapest, Hungary) for 2 weeks when their body weight reached $200-250 \mathrm{~g}$. Then animals were divided into three experimental groups. The so-called normal control group of animals was further kept on the aforementioned standard diet. The other two groups were changed to the semisynthetic pancreatotrophic raw soybean flour-based diet [27]. One of them received a single carcinogen injection 
(i.p., $30 \mathrm{mg} / \mathrm{kg}$ b.w.) of aqueous azaserine (Sigma-Aldrich Ltd., Budapest, Hungary) solution $(30 \mathrm{mg} / \mathrm{ml})[27,34]$. The rats had free access to this diet and water throughout the experimental period.

Groups of 4 animals were used 5, 6, 8, 10, 15 and 20 month after the azaserine injection. The aspecific effects of soya diet (soya control) and azaserine treatment (host tissue control) on Ub level was investigated only at month 6 after initiation. The rats were sacrificed by decapitation under ether anesthesia and their pancreata were processed for light and electron microscopy.

\section{Immunocytochemistry}

Tissue pieces were fixed for $2 \mathrm{~h}$ in $0.1 \mathrm{M}$ sodium cacodylate-HCl-buffered ( $\mathrm{pH} 7.2$ ) $2 \% \mathrm{v} / \mathrm{v}$ paraformaldehyde $/ 0.5 \%$ glutaraldehyde, containing $1 \% \mathrm{w} / \mathrm{v}$ sucrose and $2 \mathrm{mM} \mathrm{CaCl}_{2}$. Samples were post-fixed in cacodylate-buffered $1 \%$ osmium tetroxide acid solution for $1 \mathrm{~h}$. This was followed by block contrasting in $2 \%$ aquaeous uranyle acetate and embedding in Durcupan (Fluka Chemie AG, Buchs, Switzerland).

Semithin sections of the tissue samples were made and stained either with toluidine blue-Azure II, or methylene blue-basic fuchsin mixture to phenotypically determine the tumour stage. AACNs and the surrounding host tissue cells were distinguished in the light microscope by their differential morphology and basophilic staining. Adenomas and CIS of macroscopic size were isolated from the fresh tissue and processed individually for electron microscopy. At least four tumour samples were taken for ultrathin sectioning from each animal.

Immunogold labelling was carried out by a postembedding biotin-antibiotin method using affinity-purified rabbit antibody to ubiquitin-protein conjugates [12]. The sections were treated with $5 \% \mathrm{H}_{2} \mathrm{O}_{2}$ solution for $5 \mathrm{~min}$, and then washed in phosphate-buffered saline (PBS). After a blocking procedure, sections were incubated overnight at $4{ }^{\circ} \mathrm{C}$ with the antibody against Ub $(1: 100$, Dako A/S, Glostrup, Denmark). Sections were then washed in PBS-BSA-azide solution, and incubated for an hour at room temperature with biotinylated goat anti-rabbit $\operatorname{IgG}(1: 300$, Dako A/S, Glostrup, Denmark). After rinsing, sections were incubated for 5 hours at $4{ }^{\circ} \mathrm{C}$ with goat anti-biotin gold (1 : 100, Plano W. Plannet GmbH, Wetzlar, Germany), and then washed in TRIS buffer solution and nanopure water. Sections were counterstained for 5 min with lead-citrate solution.

Ten electron micrographs were taken per sample at a primary magnification of 8000 in a Jeol JEM-100 CX II electron microscope operated at $60 \mathrm{kV}$. Number of gold granules in nuclear and cytoplasmic surface was counted and density of Ub positivity was determined (number of gold in a unit area) with a measurement carried out by the point counting method as described by Weibel [33]. The Mann-Whitney $u$-test was used for statistical evaluation. 


\section{RESULTS}

There were no significant differences in Ub levels between the control cell types (normal control, soya control and host tissue control), indicating that neither soya diet nor azaserine treatment effected Ub immunoreactivity (Figs 1, 2, 3).

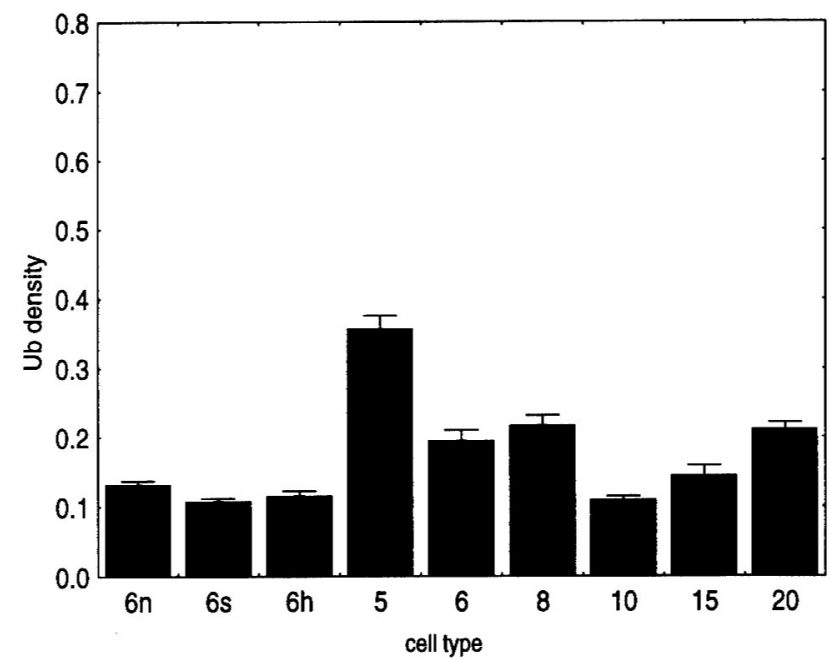

Fig. 1. Ub density on the total cell sectional surface (nucleus + cytoplasm) expressed in number of gold per unit area. $6 \mathrm{n}$ - normal control, $6 \mathrm{~s}$ - soya control and $6 \mathrm{~h}$ - host control in month $6.5,6,8$ - AACN cells in the respective month after initiation. 10,15 - adenomas in the month 10 and 15 , respectively. 20 - CIS cells in month 20

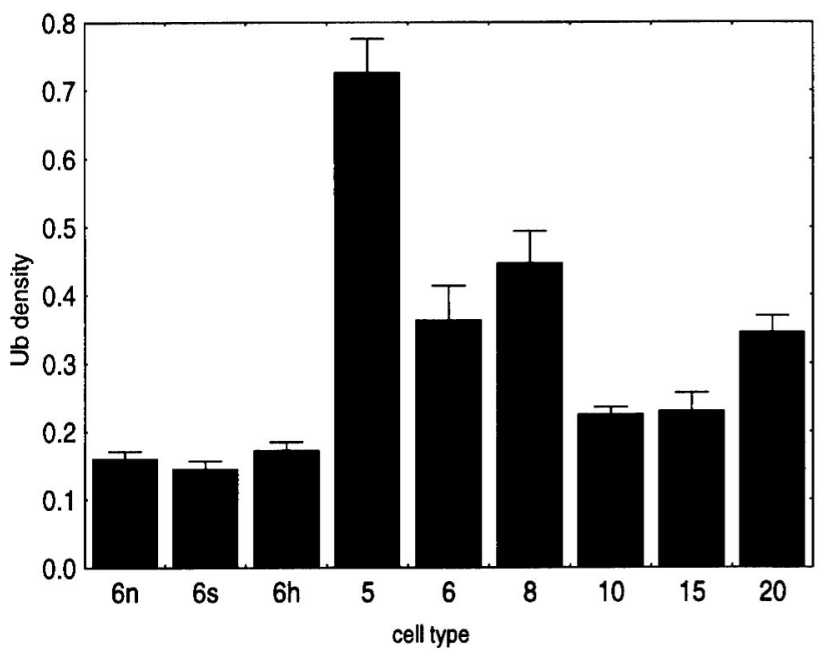

Fig. 2. Ub density on the nuclear sectional surface in number of gold per unit area. Labeling as in Fig. 1 
Significant changes were found in $\mathrm{Ub}$ positivity throughout tumour progression (Fig. 1). In month $5 \mathrm{AACN}$ cells, the total Ub density was three times higher (0.35) than that measured in any control cell type. This increased $\mathrm{Ub}$ positivity sharply decreased to its half $(0.18)$ at month 6 and remained unchanged until month 8 . Then it decreased again in adenoma cells at month 10 to the control level (0.11). From month 15 on, a slow increase in Ub density was found, its value in month 20 CIS cells reached 0.21 .

The same pattern of changes in Ub level was observed in case of nucleus and cytoplasm (Figs 2 and 3). We obtained a very high Ub density in nucleus of month 5 premalignant cells $(0.73)$, more than four times greater than that measured in control cell types (0.16). In the latter AACN cells, this value decreased to its half $(0.40)$. This fall in Ub density went on also in the benign adenoma cells (0.22), but in month 20 CIS cells, a significant increase of nuclear Ub positivity was observed again (Fig. 2).

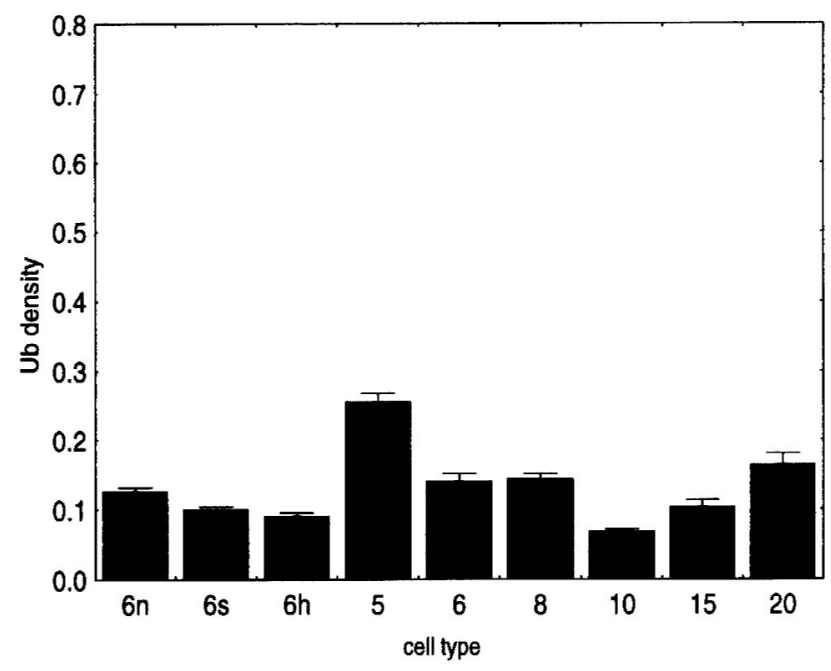

Fig. 3. Ub density on the cytoplasmic sectional surface in number of gold per unit area. Labeling as in Fig. 1

The cytoplasmic $\mathrm{Ub}$ density increased moderately in premalignant cells (from 0.10 measured in control cells to 0.25 in month 5 - and 0.14 in month 6,8 AACN cells). After a transitional decrease of Ub density in month 10 adenoma cells (0.07), malignant CIS cells showed again a significant increase of cytoplasmic Ub immunoreactivity (Fig. 3). 


\section{DISCUSSION}

Several reports have described increased intensity of Ub immunoreactivity in neoplastic cells $[10,14,17,22,25]$. Our results indicate that there are no significant changes in the level of $\mathrm{Ub}$ and/or Ub-protein conjugates due to soya diet feeding or azaserine treatment, but it changed considerably in premalignant and malignant cells throughout tumour progression.

In our experimental model, phenotypically well-determined stages were described $[20,21]$. In this report we showed that premalignant cells have an increased nuclear and cytoplasmic Ub positivity. This observation is in line with the results published recently by Osada and coworkers [25], i.e. in precancerous lesions and early hepatocarcinoma cells showed increased intensity of immunostaining according to the malignancy of the lesions. However, in our investigations, we obtained no such oneway changes throughout tumour progression. AACN cells, although showing the same phenotype exhibited different Ub levels at different time points of progression. Contrary to some recent results [22], a further moderate change in Ub immunoreactivity was observed in benign adenoma cells in month 10 and 15 after initiation. However, after the premalignant-malignant transformation, month 20 CIS cells showed again an elevated nuclear and cytoplasmic $\mathrm{Ub} / \mathrm{Ub}$-protein conjugates level. Similar result was reported in case of hepatocellular [25], and renal carcinoma [17].

It is unclear whether this changes in $\mathrm{Ub}$ immunoreactivity are due to free $\mathrm{Ub}$ or ubiquitinylated proteins. In case of hepatocellular carcinoma, no significant increase of free $\mathrm{Ub}$ level was observed [25], but an increase was shown in some ubiquitinilated proteins in tumour tissues according to the degree of malignancy $[25,26]$. The accumulation of Ub-protein conjugates which are unique to premalignant or malignant cells may most likely account for increased nuclear and/or cytoplasmic Ub immunoreactivity. Ub system overloaded by large quantity of protein to be digested could lead to an increase of Ub synthesis. These proteins may be specific for neoplastic cells, and their resistance to proteasome proteolysis might lead to their accumulation $[24,26]$. For example, in hepatocellular carcinoma, ubiquitinylated glutamine synthetase was obtained to correlate with progression [26]. In our experimental model, these proteins are not known at present.

Changes in Ub immunoreactivity may also be linked to the apoptotic process during tumour progression. Some papers revealed a possible relationship between apoptosis and the Ub pathway. Soldatenkov and coworkers [30] recently showed that $\mathrm{Ub}$ level increased in human breast carcinoma cells after apoptotic induction. A similar result was reported in case of Ewing sarcoma cells [29]. Accumulation of Ub-protein conjugates was observed specifically in cells which exhibited apoptotic morphology [30]. Several papers have recently reported that inhibition of the Ub-proteasome pathway and dysregulation of degradation of proteins involved in cell cycle and growth control caused apoptosis in malignant cells $[1,11]$. This observation may be another possible explanation for the elevated $\mathrm{Ub}$ immunoreactivity, because a part of AACNs are supposed to rapidly regress, and a great number of apoptotic cells was observed in the malignant CIS stage. Since the ubiquitin-proteasome apparatus is 
responsible for the degradation of some proteins playing a critical role in apoptotic process, upregulation of their degradation may be a novel survival mechanism in tumour cells [19].

In our experiment, the most intensive increase was observed in the nuclear Ub immunoreactivity of premalignant and malignant cells. In transformed human cells, an increased level of ubiquitinated histone $\mathrm{H} 2 \mathrm{~A}$ was found compared to that in normal cells [32]. Interestingly, these Ub-histone conjugates disappeared in induced apoptosis [23].

To summarize our results, we showed that the level of Ub and/or Ub-protein conjugates significantly changed throughout tumour progression. We found two peaks of $\mathrm{Ub}$ immunoreactivity, first at the premalignant stages (especially in month $5 \mathrm{AACN}$ cells) and then in malignant CIS cells. Identification of ubiquitinylated proteins in our system will hopefully shed light on the background of this phenomenon.

\section{ACKNOWLEDGEMENTS}

We would like to thank Sarolta Pálfia, Ágnes Keserü and Mariann Saródy for their excellent technical assistance. This study was partly supported by a Copernicus Contract (CIP-ACT 930210) of the European Union.

\section{REFERENCES}

1. Adams, J., Palombella, V. J., Sausville, E. A., Johnson, J., Destree, A., Lazarus, D. D., Maas, J., Prakash, S., Elliott, P. J. (1999) Proteasome inhibitors: a novel class of potent and effective antitumor agents. Cancer Res. 59(11), 2615-2622.

2. Alves-Rodrigues, A., Gregori, L., Figueiredo-Pereira, M. E. (1998) Ubiquitin, cellular inclusions and their role in neurodegeneration. Trends Neurosci. 21(12), 516-520.

3. Arnold, J., Dawson, S., Fergusson, J., Lowe, J., Landor, M., Mayer, R. J. (1998) Ubiquitin and its role in neurodegeneration. Prog. Brain Res. 117, 23-34.

4. Chau, V., Tobias, J. W., Bachmair, A., Marroiott, D., Ecker, D. J., Gonda, D. K., Varshavsky, A. (1989) A multiubiquitin chain is confined to specific lysine in a targeted short-lived protein. Science $243,1576-1583$.

5. Ciechanover, A., DiGiuseppe, J. A., Bercovich, B., Orian, A., Richter, J. D., Schwartz, A. L., Brodeur, G. M. (1991) Degradation of nuclear oncoproteins by the ubiquitin system in vitro. Proc. Natl. Acad. Sci. USA 88, 139-143.

6. Ciechanover, A. (1994) The ubiquitin-proteasome proteolytic pathway. Cell 79, 13-21.

7. Ciechanover, A., Orian, A., Schwartz, A. L. (2000) The ubiquitin-mediated proteolytic pathway: mode of action and clinical implications. J. Cell Biochem. Suppl. 34, 40-51.

8. Finch, J. S., John, T. S., Krieg, P., Bonham, K., Smith, H. T., Fried, V. A., Bowden, G. T. (1992) Overexpression of three ubiquitin genes in mouse epidermal tumors is associated with enhanced cellular proliferation and stress. Cell Growth Differ. 3, 269-278.

9. Finley, D., Ozhaynak, E., Varshavsky, A. (1987) The yeast polyubiquitin gene is essential for resistance to high temperatures, starvation, and other stresses. Cell 48, 1035-1046.

10. Galloway, P. G., Likavec, M. J. (1989) Ubiquitin in normal, reactive and neoplastic human astrocytes. Brain Res. 500, 343-351.

11. Golab, J., Stoklosa, T., Czajka, A., Dabrowska, A., Jakobisiak, M., Zagozdon, R., Wojcik, C., Marczak, M., Wilk, S. (2000) Synergistic antitumor effects of a selective proteasome inhibitor and TNF in mice. Anticancer Res. 20(3A), 1717-1721. 
12. Haas, A. L., Bright, P. M. (1985) The immunochemical detection and quantitation of intracellular ubiquitin-protein conjugates. J. Biol. Chem. 260, 12464-12473.

13. Hershko, A., Ciechanover, A. (1986) The ubiquitin pathway for the degradation of intracellular proteins. Prog. Nucleic Acid Res. Mol. Biol. 33, 19-56.

14. Ishibashi, Y., Takada, K., Joh, K., Ohkawa, K., Aoki, T., Matsuda, M. (1991) Ubiquitin immunoreactivity in human malignant tumors. Br. J. Cancer 63, 320-322.

15. Iwaya, K., Nishibori, H., Osada, T., Matsuno, Y., Tsuda, H., Sato, S., Kono, H., Fukutomi, T., Suzuki, M., Torikata, C., Iwamatsu, A., Hirohashi, S. (1997) Immunoreaction at $43 \mathrm{kDa}$ with anti-ubiquitin antibody in breast neoplasms. Jpn. J. Cancer Res. 88(3), 273-280.

16. Jennissen, H. P. (1995) Ubiquitin and the enigma of intracellular protein degradation. Eur. J. Biochem. 231, 1-30.

17. Kanayama, H., Tanaka, K., Aki, M., Kagawa, S., Miyaji, H., Satoh, M., Okada, F. (1991) Changes in expressions of proteasome and ubiquitin genes in human renal cancer cells. Cancer Res. 51, $6677-6685$

18. La Rosa, F. G., Kumar., S., Prasad, K. N. (1996) Increased expression of ubiquitin during adenosine 3',5'-cyclic monophosphate-induced differentiation of neuroblastoma cells in culture. J. Neurochem. 66(5), 1845-1850.

19. Li, B., Dou, Q. P. (2000) Bax degradation by the ubiquitin/proteasome-dependent pathway: involvement in tumor survival and progression. Proc. Natl. Acad. Sci. USA 97(8), 3850-3855.

20. Longnecker, D. S., Roebuck, B. D., Yager, J. D., Lilja, H. S., Sigmund, B. (1981) Pancreatic carcinoma in azaserine-treated rats: induction, classification and dietary modulation of incidence. Cancer, $47,1562-1572$.

21. Longnecker, D. S. (1986) Experimental models of exocrine pancreatic tumors. In: Go, V. L. W., Gardner, J. D., Brooks, F. P., Lebenthal, E., Di Magno, E. P., Scheele, G. A. (eds) The exocrine pancreas biology, pathobiology and diseases. Raven Press, New York. pp. 443-458.

22. Marin, F., Cheng, Z., Kovács, K. (1993) Ubiquitin immunoreactivity in corticotrophs following glucocorticoid treatment and in pituitary adenomas. Arch. Pathol. Lab. Med. 117, 254-258.

23. Marushige, Y., Marushige, K. (1995) Disappearance of ubiquitinated histone H2A during chromatin condensation in TGF beta 1-induced apoptosis. Anticancer Res. 15(2), 267-272.

24. Nishibori, H., Matsuno, Y., Iwaya, M., Osada, T., Kubomura, N., Iwamatsu, A., Kohno, H., Sato, S., Kitajima, M., Hirohashi, S. (1996) Human colorectal carcinomas specifically accumulate Mr 42.000 ubiquitin-conjugated cytokeratin 8 fragments. Cancer Res. 56(12), 2752-2757.

25. Osada, T., Sakamoto, M., Ishibori, H., Iwaya, K., Matsuno, Y., Muto, T., Hirohashi, S. (1997) Increased ubiquitin immunoreactivity in hepatocellular carcinomas and precancerous lesions of the liver. J. Hepatol. 26, 1266-1273.

26. Osada, T., Sakamoto, M., Nagawa, H., Yamamoto, J., Matsuno, Y., Iwamatsu, A., Muto, T., Hirohashi, S. (1999) Acquisition of glutamine synthetase expression in human hepatocarcinogenesis: relation to disease recurrence and possible regulation by ubiquitin-dependent proteolysis. Cancer 85(4), 819-831.

27. Réz, G., Tóth, S, Pálfia, Z. (1999) Cellular autophagic capacity is highly increased in azaserineinduced premalignant atypical acinar nodule cells. Carcinogenesis 20, 1893-1898.

28. Shimbara, N., Sato, C., Takashima, M., Tanaka, T., Tanaka K., Ichihara, A. (1993) Down-regulation of ubiquitin gene expression during differentiation of human leukemia cells. FEBS Letters 322(3), 235-239.

29. Soldatenkov, V. A., Dritschilo, A. (1997) Apoptosis of Ewing's sarcoma cells is accompanied by accumulation of ubiquitinated proteins. Cancer Res. 57(18), 3881-3885.

30. Soldatenkov, V. A., Prasad, S., Voloshin, Y., Dritschilo, A. (1998) Sodium butyrate induces apoptosis and accumulation of ubiquitinated proteins in human breast carcinoma cells. Cell Death Differ. 5, $307-312$.

31. Spataro, V., Norbury, C., Harris, A. L. (1998) The ubiquitin-proteasome pathway in cancer. Br. $J$. Cancer 77(3), 448-455. 
32. Vassilev, A. P., Rasmussen, H. H., Christensen, E. I., Nielsen, S., Celis, J. E. (1995) The levels of ubiquitinated histone $\mathrm{H} 2 \mathrm{~A}$ are highly upregulated in transformed human cells: partial colocalization of uH2A clusters and PCNA/cyclin foci in fraction of cells in S-phase. J. Cell Csi. 108(3), $1205-1215$.

33. Weibel, E. R. (1969) Stereological principles for morphometry in electron microscopic cytology. Int. Rev. Cytol. 26, 235-302.

34. Yager, J. D., Roebuck, B. D., Zurlo, J., Longnecker, D. S., Weselcouch, E. O., Wilpone, S. A. (1981) A single-dose protocol for azaserine initiation of pancreatic carcinogenesis in the rat. Int. J. Cancer $28,601-606$. 